\title{
Research on the Culture Connotation of English Vocabulary
}

\author{
Jing Yang \\ Zhengzhou University of Industrial Technology, Henan, China
}

414153761@qq.com

Keywords: vocabulary; culture connotation; English teaching.

\begin{abstract}
With the rapid development of the internationalization, the exchanges between culture and ideology have become an indispensable way, but the exchanges could not exist without language. Vocabulary, as one of the three elements of language, not only represents a single conceptual significance, but also has its own culture connotation which represents the culture background of birth of the vocabulary, history development and the present situations of all aspects of society. This paper aims at making many scholars pay more attention to the culture connotation of English vocabulary and putting forward the rationalization proposals to strengthen the focus of the teachers and students on the culture connotation of vocabulary in English learning.
\end{abstract}

\section{Introduction}

The Chinese linguist Huang Shijian said, "In terms of the history of Chinese and foreign relations, I feel that linguistics is a very important discipline” [13]. Language, as an indispensable role in culture, can directly make countermeasures to the social and culture changes. Language mainly reflects its meaning in culture by vocabulary. Therefore, fundamentally speaking, the vocabulary is the cornerstone of culture which can reflect a unique national culture and development process. Vocabulary, which can clearly record the development of a nation's history, looks like the cloud storage of contemporary society. A unique and long culture form can easily be understood through the vocabulary. The culture connotation of vocabulary refers to the meaning of the vocabulary in the language that is closely related to the history, culture, customs and habits of the country in which the language is spoken. If a country has a longer history, its unique vocabulary will have more rich culture connotation. So it is necessary to understand the true colors behind the vocabulary.

Through the study, combining the theory and practice, the paper will strengthen the accumulation and application of culture knowledge, and will also be helpful to English teaching.

\section{Language, Culture and Vocabulary}

\subsection{Definition}

What is language? Over the years, many linguists, sociologists and philosophers in China and the West have defined the language from different views and fields. After accepting Lenin's “Language is the most important human communication tools"[3] in the fifties, Chinese linguists began to calmly solve various problems in research. As time goes by, language research will also usher in a new test. The Professor Wang Xijie pointed out that language, as the most important human communication and thinking tools, was a special social phenomenon and a symbol system by the combination of syllable and meaning. In a word, language should not be limited to literal meaning, which is a tool for people to exchange ideas, emotions and desires.

For the culture, there is not a very clear definition: The British anthropologist Tayor put forward the classic definition of culture which appeared in 1871 in the book Original Culture, "Culture is a complex unity which includes knowledge, belief, art, law, morals, custom, and any other capabilities and habits acquired as a member of society"[2]. The modern culture anthropologists believes that Taylor's definition on culture only focuses on the spirit of the culture and it is not complete. They think that culture, which includes material and spiritual aspects, is a group of activities; the material which people create is the material culture; regulations and systems completely belong to the culture level; Human's belief is the pursuit of the spiritual level. 
Vocabulary is a collective concept, which means a unity converged by all the words in language. Stalin said that all the words in the language made up the vocabulary of the so-called language. Later, Zhang Shilu thought that the role of some fixed phrase in the language was equivalent to a word. With the deepening of lexicology research, people's understanding on vocabulary has made great improvement. Zhang Yongyan held that the so-called vocabulary was the sum of the equivalents of the words in the language (such as fixed phrases).

\subsection{The Relationships Between Language and Culture}

In China, the study on the relationships between language and culture began in the 1950s, produced rich and high quality results in the 1980s. At the same time, some new theories appear in the new century.

B. W. Robinett, in the book Teaching English to Speakers of Other Language, said, "Language is a tool of society and its use of language reflects the culture of a society"[1]. H. Goodenough said that the language of a society was one aspect of the culture of society, language was a part of the culture. This argument emphasizes the close relationship between language and culture. Language is a part of culture, which is a special culture phenomenon. In the process of social progress, language provides a basic platform for the development of Human society.

According to the composition of culture, the anthropologists divide culture into four major systems: economic systems, social systems, conceptual systems, and language systems. Language can record culture development process clearly and roundly. Although the vocabulary can record the culture, it is only a symbol of language. So language is the most important carrier of culture.

Due to the different culture characteristics and history background, it is necessary to firstly understand the vocabulary before understanding the culture of a region or nation, and then investigate the culture connotation. Only in this way can it clearly transfer Culture information to each other. Therefore, it is very important to make a research on the culture connotation of English vocabulary at first.

\section{The Manifestations of Culture Connotation}

\subsection{Culture Overlap}

The same thing has the same culture connotation, which phenomenon is called culture overlap. Language carries the culture, the connotation meaning of vocabulary deeply roots in the history which is created by human during thousands of years. These culture connotations involve a wide range, including social history, religious beliefs and customs. Many cultures are the material and spiritual fruits of all human being activities. With the development of human society and the accumulation of practical experience, some phenomena and people's psychological feelings form a fixed correspondence gradually. Therefore, the culture connotation of different vocabulary has the same meaning. People use the same logical reasoning methods to understand the literal meaning and connotation meaning. Here are some examples:

Strike the iron while hot: Chen re da tie (Chinese Pinyin) -Take advantages of a good time to do things well.

One stone kills two birds: Yi shi shuang niao (Chinese Pinyin) -To achieve two purposes by doing one thing.

Cold war: Leng zhan(Chinese Pinyin) -Internationally carries out the struggle against weapons.

\subsection{Culture Discrepancy}

Because of the different geographical environment and the different ways of life, the same kind of things also exist different culture connotation in a certain national culture. Here are some examples:

Dragon: According to the interpretation from the book Unabridged Dictionary, dragon is a king of miraculous animal which can bear supernatural powers to summon wind and call for rain in the ancient legend. In the hearts of the Chinese people, dragon is a symbol of elegance. In the feudalistic age, dragon, which was a symbol of supreme, always was used to refer to the emperor. In English, "dragon" is a kind of evil and ugly animal. In the Bible, the dragon is killed by George with a shuttle dart. Westerners uses the vocabulary "dragon” to call the violent and harsh people. 
In white: In Chinese culture, when one member of the family died, the other members should wear white filial piety to express the mourning of the deceased in the funeral time. In the Western customs, when married, the bride should wear a white mopping dress to express the holiness and innocence of the love.

Go die: In China, the vocabulary is produced from a rap by the singer Huang Zitao, and then it is translated as "Gou dai" because of the homonym. It is used to express the unyielding attitude. But in the UK, the description of the Urban dictionary says, "go die" is used for the status that one person did not have to be bothered by the conversation of others. If a person always feels irritability, the person could be so straightforward to reject each other in a lightning speed. It is a very practical way to say "No".

\subsection{Vocabulary Vacancies}

The same kind of things has connotation in one culture but no connotation in another culture, which only has the intention meaning. This status leads to the situation that only one language has culture connotation. Linguists call the phenomenon "Vocabulary vacancy". Here are some examples:

Bamboo: Because of the environmental factors of the Anglo-American countries, there is little bamboo in the nation, so bamboo almost has no connotation meaning in English. The difference is that the Chinese "zhu” is inextricably linked with the traditional Chinese culture. China's Qing Dynasty poet Zheng Banqiao expressed the high praise to the tough character of bamboo. The verse in the poem bamboo stone was "From whichever direction the winds leap; I remain strong, though encountered many blows".

Onion: In Chinese, it has only conceptual meaning. But in English, "to have one’s onions” means "experience-based knowledge".

Bread and Butter: Bread and butter have no connotation meaning in Chinese. But in English its meaning is "the way to make a living".

\subsection{Proprietary Vocabulary}

In the national culture, there are some unique vocabularies which have distinct culture connotation. They are a mirror of national culture. Such as, God, cross, wine, whiskey, turkey, coffee and so on.

"God" is the most important part of Western religious culture. Catholicism and Christianity believe in God. As time goes by, the faith to God has become a part of people's daily life. Even today, if someone is injured, the other people will say "God bless you". In the US presidential inaugural ceremony, the new president will put his hand on the Bible and says "In the name of God, I make this promise..."; In court, the witness before the testimony need to raise their hands to swear "In the name of God, I swear that every word I say is truth”.

\section{Suggestions on Teaching}

\subsection{Survey Objects}

The information is collected by the way of online survey in the questionnaire. The Survey object is involved in the investigation, containing 60 students from Zhengzhou University of Industrial Technology and 20 students from Anyang Institute of Technology. These students come from 6 different majors.

\subsection{Survey Contents}

The questionnaire contains two parts: the questions of investigation, and personal information.

This questionnaire put forward nine questions combines with the current situations of vocabulary teaching in modern university: Whether the respondents have ever heard of the English linguist Jeffrey Leach's theory of the "classification of lexical meaning"; Whether the respondents know the culture connotation of English vocabulary; Whether the respondents know the status of cross-culture communication; Whether the English teachers lead the students to fully review the English vocabulary before each lesson; In the teaching process, whether the English teachers have some comparative educations on special English vocabulary with the way by combining with relevant background; In the learning process, whether the English teachers incorporate English vocabulary into a special context; In the learning process, whether the English teachers arrange some discussion sessions on English vocabulary; At the end of the course, whether the English teachers arrange for 
high-frequency vocabulary to expand understanding of the tasks, such as fixed match; After the end of the course, whether the students take the initiative to remember the vocabulary according to the memory methods taught by the English teachers.

The options for the questions are set to be totally incompatible, rarely meet, some or part of, basic compliance, fully consistent.

Personal information includes name, professional, contact information and suggestions.

\subsection{Survey Results}

According to the survey, 95\% of the students have not heard of the theory "Leach's classification of lexical meaning", $5 \%$ of students choose "some or part of"; When the students answer the two questions "whether the respondents know the culture connotation of English vocabulary and the status of cross-culture communication", 75\% of the students choose "rarely meet", $18.75 \%$ of the students choose "some or part of", $6.25 \%$ of the students choose "basic compliance"; In answering the question "Whether the English teachers lead the student to fully review the English word before each lesson", $37.5 \%$ of the students choose "completely incompatible", $50 \%$ of the students choose "some or part of", $12.5 \%$ of the students choose "basic compliance"; In answering the question "In the teaching process, whether the English teachers have some comparative education on special English vocabulary with the way by combining with relevant background", $80 \%$ of the students choose "totally incompatible", 20\% of the students choose "some or part of"; In answering the question "In the learning process, whether the English teachers incorporate English vocabulary into a special context", $25 \%$ of the students choose "rarely meet", $75 \%$ of the students choose "some or part of"; In answering the question "In the learning process, whether the English teachers arrange some discussion sessions on English vocabulary", 100\% of the students choose "totally incompatible"; In answering the question "At the end of the course, whether English teachers arrange for highfrequency vocabulary to expand understanding of the tasks, such as fixed match", $25 \%$ of the students choose "rarely meet", $68.75 \%$ of the students choose "some or part of", $6.25 \%$ of the students choose "basic compliance"; In answering the question "After the end of the course, whether the students take the initiative to remember the vocabulary according to the memory methods taught by the English teachers", $80 \%$ of the students choose "some or part of", $12.5 \%$ of the students choose "basic compliance" and $7.5 \%$ of the students choose "fully consistent".

In the personal information, 16 students put forward their suggestions, 12 students reflects the classroom atmosphere is boring.

\subsection{Analysis of Results}

Based on the above survey results, the questionnaire shows that almost all college students have not heard of Leach's seven meanings of vocabulary; only a small number of college students know the culture connotation and the current situation of cross-culture communication, which means that the current college students lack the consciousness of "theory with practice"; in the process of vocabulary teaching, English teachers still pay more attention to previewing vocabulary before class, but at the same time, only a small number of English teachers have some comparative educations on special English vocabulary with the way by combining with relevant background, although the vocabulary will be put into a certain context, but lacking of contrast, which is difficult for students to understand thoroughly; in the learning process, the English teachers almost do not arrange the discussion on the vocabulary culture connotation, making the classroom atmosphere boring; after the end of the course, most of the English teachers will arrange to expand learning tasks; most of the students will take the initiative to memorize the words in accordance with the English teachers' memory skills, which are good for training the ability of self-taught and self-learning. Thus, there are three basic problems in the process of teaching college English: without paying enough attention to the culture connotation of English vocabulary, lack of consciousness of "theory with practice"; lack of the depth of teaching; the boring classroom atmosphere.

\subsection{Suggestions}

According to the above problems in the process of English teaching, some suggestions are put forward. 
First of all, teachers must understand that the purpose of learning is not to complete the task of learning and survive the university final examinations of four years, but to learn the knowledge applied to their own lives and work. So English teachers should cultivate students to develop the sense of "theory with practice" and lead students to achieve the unity of learning and life. And then the vocabulary is the most powerful way of expression of culture. If English teachers cannot bring English culture into the vocabulary, it is difficult to avoid the Chinese-style foreign language teaching, and students will encounter all kinds of obstacles.

As Lado said, "By comparing the learning language and mother tongue with its culture of students, we can predict and describe where there is difficulty in the learning process and where there is no difficulty"[15]. Therefore, in foreign language teaching, English teachers should have some comparative educations on special English vocabulary by the multi-faceted and multi-angle form combining with the vocabulary culture background, especially synonyms. The aim is to avoid the embarrassing situation which may occur in cross-culture communication in the future.

The survey shows that many students reflect the classroom atmosphere is boring, and it is difficult to insist on putting their hearts on learning. It is well known that interest is the best mentor of a person. People will promote the efficiency of learning in a pleasant atmosphere. In the university teaching, English teachers should make the classroom atmosphere active, and carry out some interactive activities. Discussion activities can not only deepen the depth of students' understanding, open up the way of students' thinking, but also can promote the exchanges between students. Competition activities can exercise the students' temporary response ability and cultivate students' interest in learning.

\section{Conclusion}

Vocabulary is not only the most representative element of culture, but also the largest factor in culture load. The culture connotation of the vocabulary shows the development of a nation's history in many ways, directly highlighting the differences between cultures. Mastering the culture connotation of English vocabulary is the basic ability that each student should have, which is irreplaceable in the future of cross-culture communication. At the same time, English teaching should be a diversified trend. English teachers should not simply explain the vocabulary and increase the quantity of student's vocabulary. English teachers should try their best to penetrate the culture connotation into each vocabulary as much as possible and to cultivate students the sense of "theory with practice”. Therefore, both teachers and students should be aware of the importance of the culture connotation of English vocabulary.

In real life, college students should learn new things with purpose and focus on the development of the society. In the process of vocabulary learning, students should follow the trend of the times, understand the current situation of cross-culture communication, apply the theory to the practice and dare to seek knowledge. In practice, college students should learn the background and the culture connotation of English vocabulary, and then give the vocabulary new meaning by combing with the development of the new era. Finally, with the development of the era, English vocabulary will be more mature, the research on English vocabulary will also be innovative. Students should be brave to find new ideas.

\section{Acknowledgments}

This paper is funded by the Research Project of Henan Social Science Union, the Project Number is SKL- 2017 - 1514.

\section{References}

[1]. Alan, Cruse. Meaning in Language [M]. New York: Oxford University Press, 2004.

[2]. Burnett Tylor, Edward. Original Culture [M]. Guangxi: Guangxi Normal University Press, 2005: 12. 
[3]. Compilation and Translation Bureau of the CPC central committee. Lenin corpora (Volume 25)[M]. Beijing: Renmin Press, 1988: 224.

[4]. Claire, Kramsch. Language and Culture [M]. Shanghai: Shanghai Foreign Language and Education Press, 2000.

[5]. Gail E, Tompkins \& Cathy L, Blanchfield. Teaching Vocabulary [M]. London: Pearson Higher Isia Education, 2007.

[6]. H. D. Brown. Principles of Language learning and Teaching [M]. Beijing: Foreign Language Teaching and Research Press, 2002.

[7]. H. D. Brown. Tips for Teaching Culture: Practical Approaches to Intercultural Communication [M]. Beijing: The Tsinghua University Press, 2015.

[8]. Joan Kelly Hall. Teaching and Researching Language and Culture [M]. Beijing: Foreign Language Teaching and Research Press, 2005.

[9]. Lado, Robert. Linguistics across Cultures: Applied Linguistics for Language Teacher [M]. (Michigan: University Of Michigan Press, 1957, 1.

[10]. Linell, Davis. “Cross-cultural Communication in Action” [J]. Doing Culture, 179, 2001(1) : 109-114.

[11]. Nida, Eugene Albert. Language, Culture, and Translating [M]. Shanghai: Shanghai Foreign Language Education Press, 2001.

[12]. Samovar, Larry A \& Porter, Richard E. Communication Between Cultures (3nd ed) [M]. Beijing: Foreign Language Teaching and Research Press, 2000.

[13]. Shilin Zhang. Xue Lin Chun Qiu[M]. Beijing: Zhao Hua Press, 1999: 512.

[14]. Shuzhi Cui. The relationship between language teaching and cultural background knowledge[J]. Journal of Shanghai foreign studies university, 1986 (1).

[15]. Lado, Robert. Linguistics across Cultures: Applied Linguistics for Language Teacher [M]. Michigan: University Of Michigan Press, 1957:20. 